\title{
Diacronie
}

Studi di Storia Contemporanea

$\mathrm{N}^{\circ} 24,4 \mid 2015$

Le dittature militari: fisionomia ed eredità politica

\section{El funcionamiento del Dispositivo Generador de Identidades durante la última dictadura militar argentina (1975-1983)}

Ariel Ignacio Slavutsky

\section{(2) OpenEdition \\ Journals}

Edición electrónica

URL: http://journals.openedition.org/diacronie/3669

DOI: 10.4000/diacronie.3669

ISSN: 2038-0925

Editor

Association culturelle Diacronie

Referencia electrónica

Ariel Ignacio Slavutsky, « El funcionamiento del Dispositivo Generador de Identidades durante la última dictadura militar argentina (1975-1983) », Diacronie [En línea], № 24, 4 | 2015, documento 5, Puesto en línea el 29 diciembre 2015, consultado el 19 abril 2019. URL : http:// journals.openedition.org/diacronie/3669; DOI : 10.4000/diacronie.3669 


\title{
Diacronie
}

\section{El funcionamiento del Dispositivo Generador de Identidades durante la última dictadura militar argentina (1975-1983)}

\author{
Ariel Ignacio SLAVUTSKY *
}

A lo largo de este artículo nos proponemos analizar el desarrollo de un dispositivo que hemos denominado generador de identidades (DGI). Desde sus inicios el Estado Nación moderno puso en marcha una particular manera de lidiar con los 'otros' culturales al interior de su territorio. En términos generales se trataba de establecer como mínimo dos estrategias: el monopolio de la fuerza por un lado; y el desarrollo de una serie de instituciones educativas y culturales que le asegurasen una posición hegemónica para fortalecer un proyecto identitario nacional. En este trabajo nos proponemos analizar como la última dictadura militar argentina reutilizó este sistema institucional con la finalidad de fortalecer una identidad Occidental y cristiana.

\section{El uso del concepto de dispositivo}

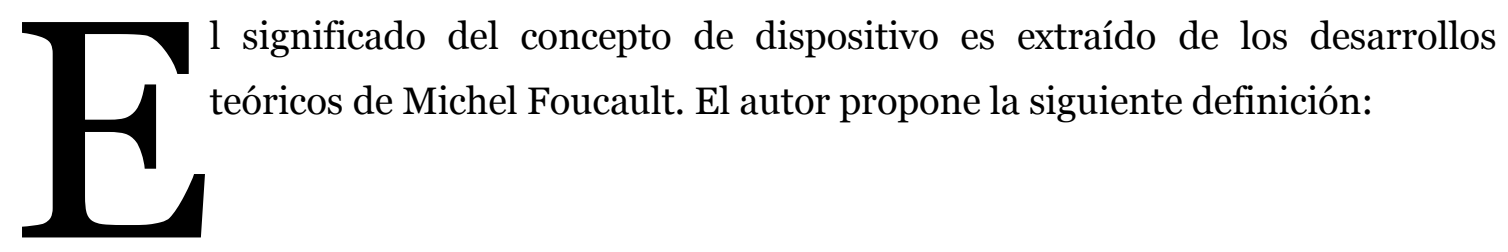

son un conjunto decididamente heterogéneo, que comprende discursos, instituciones, instalaciones arquitectónicas, decisiones reglamentarias, leyes, medidas administrativas, enunciados científicos, proposiciones filosóficas, morales, filantrópicas; en resumen: los elementos del dispositivo pertenecen tanto a lo dicho 
como a lo no dicho. El dispositivo es la red que puede establecerse entre estos elementos, [...] En segundo lugar, lo que querría situar en el dispositivo es precisamente la naturaleza del vínculo que puede existir entre estos elementos heterogéneos [...] En tercer lugar, por dispositivo entiendo una especie - digamos de formación que, en un momento histórico dado, tuvo como función mayor la de responder a una urgencia. El dispositivo tiene pues una posición estratégica dominante ${ }^{1}$.

Definido de esta forma, un dispositivo se organiza como una red de elementos que funcionan como espacios de enunciación y de prácticas sociales relacionados entre sí por un entramado de sentidos que se configuran en un espacio y tiempo específico. En otras palabras, surge como una herramienta de control social que se propone imponer una lógica hegemónica. Ahora bien, toda red se constituye de hilos que sirven de nexos relacionales entre una parte y otra, generando un canal de comunicación, un "entre sí”, un espacio que no pertenece ni a un elemento ni al otro pero que al mismo tiempo es constitutivo de las relaciones sociales. Es justamente ese "entre sí" - es decir la red que relaciona los distintos elementos- sobre el que haremos foco en este trabajo.

Cada elemento de esta red presenta características discursivas y lógicas prácticas distintas ${ }^{2}$, actúan, valoran y enuncian de diferentes maneras. En los términos utilizados por Bourdieu, tienen autonomía relativa. Nos detendremos brevemente en la teoría del campo propuesta por este último. El autor del Sentido Práctico propone analizar el mundo en esferas de acción con una cuota de autonomía. Dentro de estos submundos, se llevan a cabo prácticas sociales que confluyen en una particular forma de valorar el capital: simbólico, económico, académico, político, etc. A partir de este elemento en común se establecen ciertas reglas de juego - principios generadores- que el autor identifica como habitus. Este, se configura como una estructura estructurante estructurada es decir, como un sistema de normas aprendidas que se objetiva a partir de su repetición a lo largo de la Historia.

Resumiendo lo dicho, nos encontramos en un espacio específico donde circulan personas que comparten una particular forma de valorar el capital y ciertas reglas que les permiten interactuar "entre sí". En esta interacción juega un rol importantísimo el espacio que se constituye como un campo de acción de estos agentes tomando las lógicas impuestas por los habitus. Ahora bien, las personas en estos espacios no se proponen solo reproducir sus vidas sino también intentar acumular el mayor capital

${ }^{1}$ FOUCAULT, Michel, Saber y verdad, Madrid, La piqueta, 1991, p. 128.

2 Utilizamos este concepto en el sentido utilizado por BOURDIEU, Pierre, El sentido práctico, Buenos Aires, Siglo XXI Ed., 2007. 
posible para poder ocupar una mejor posición en el campo. Lo que el autor propone es una lógica de competencias, de tipo capitalista, en el que el que posea mayor habilidad para reconocer las condiciones del campo podrá ganar el juego.

Es justamente en este último punto donde el autor introduce una variable crucial para relativizar la reproducción automática del campo. En efecto los agentes poseen reflexividad lo que les permite interpretar su realidad e interpelar las reglas para poder transformarlas. Es esto lo que el autor denomina lógicas prácticas. Estas lógicas no responden a un sentido puramente económico sino que en muchas ocasiones se manifiestan como elementos contradictorios a una lógica matemática poniendo por encima del juego elementos externos a los habitus, como son los sentimientos. A pesar de este elemento disruptivo no debemos engañarnos, las estructuras suelen tener éxito y es por ello que a las Ciencias Sociales les es más dado analizar los discursos hegemónicos como un núcleo duro de ideas, sin grietas. Nuestra propuesta apunta a elaborar un discurso científico que transite los resquicios de los dispositivos, ese "entre sí”.

Comprender como funcionan las autonomías relativas de los campos a la que hemos hecho referencia anteriormente es crucial para descubrir las grietas del discurso hegemónico. La autonomía de los campos se mide a partir de esta ecuación: cuanto más heterónomo es un campo, más imperfecta es la competencia y más legítimo resulta que los agentes hagan intervenir fuerzas no científicas en las luchas científicas. Al contrario, cuanto más autónomo es un campo y más cerca está de una competencia pura y perfecta, más puramente científica es la censura, que excluye la intervención de fuerzas meramente sociales 3 .

En otras palabras la autonomía o heteronomía de un campo es directamente proporcional al grado de perfección de la competencia y dado que la competencia perfecta no existe, siempre está presente la posibilidad de vulnerar la autonomía de los campos haciendo jugar otras fuerzas. Conviene aclarar que cada elemento del DGI posee una dinámica propia, en este sentido cada uno de ellos tiene una particular forma de organizar las relaciones de poder al interior del campo. En condiciones de baja autonomía, como la que analizaremos, los habitus y lógicas prácticas se mantienen como parte de una ficción de continuidad, lo que permite a los agentes mantener una suerte de seguridad ontológica ${ }^{4}$. Una forma de grafica de representar el DGI sería a

3 BOURDIEU, Pierre, Los usos sociales de la ciencia, Buenos Aires, Quae, 2008, p. 85.

4 GIDDENS, Anthony, La constitución de la sociedad. Bases para la teoría de la estructuración, Buenos Aires, Amorrortu Ed., 2003. 
partir de un objetivo central y varios elementos circundantes conectados mutuamente entre sí y con el objetivo central.

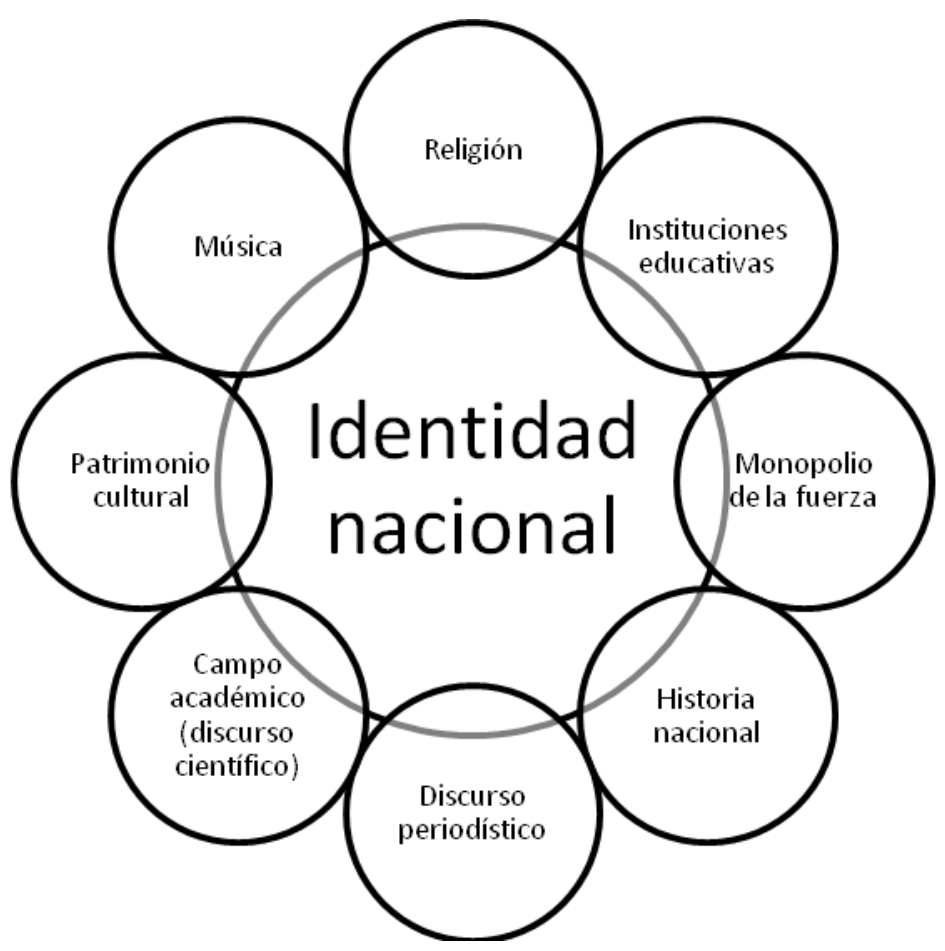

Bourdieu, acostumbrado a pensar en Francia ve una mayor separación entre los distintos campos de acción, sin embargo en la Argentina los campos suelen estar más predispuestos a interceptarse mutuamente.

\section{El DGI durante el Proceso de Reorganización Nacional}

En el período que estudiamos esta autonomía se diluye a partir de la puesta en práctica del terrorismo de Estado. En efecto, la dictadura se propuso reorganizar las relaciones de poder5 por lo que intervino directamente sobre los espacios y las prácticas. Hemos preferido utilizar el concepto de Estado Terrorista desarrollado por Duhalde $^{6}$ dado que muestra con mayor nitidez el rol moderno y estatal del proyecto genocida. Desde esta óptica el Estado Terrorista posee una doble faceta una pública en la que se manifiesta como el sostén del orden y una privada donde se desarrolla el aparato genocida. A nuestro entender ambos espacios públicos y privados estaban mutuamente imbricados dado que como veremos más adelante la reinterpretación del

5 Véase: FEIERSTEIN, Daniel, El genocidio como práctica social. Entre el nazismo y la experiencia argentina, Buenos Aires, Fondo de Cultura Económica, 2007.

${ }^{6}$ DUHALDE, Eduardo Luis, El Estado Terrorista argentino. Quince años después, una mirada crítica, Buenos Aires, Colihue, 2013. 
DGI - un acto público y dentro de las potestades estatales normales - precisó del aparato represivo genocida.

Este esfuerzo se relaciona con un doble proceso que muchos autores identifican con la lógica amigo/enemigo, que en términos identitarios podría ser traducida como mismidad/otredad. En este sentido la intervención militar implicó un doble esfuerzo: la negación de la identidad enemiga sintetizada en la imagen del "subversivo-delincuente" y al mismo tiempo la afirmación de aquello considerado como lo propio, es decir lo occidental y cristiano. Esto puede ser dicho también del proceso de organización nacional llevado a cabo a fines del siglo XIX. Así la violencia física y simbólica es constitutiva de la formación de los Estados modernos y por ende de las identidades nacionales.

El desarrollo del aparato desaparacedor7, pretendió generar la destrucción física y simbólica de muchos activistas políticos fueran estos revolucionarios o no. Una de las formas de negación simbólica, implicaba la unificación de cualquier postura política por más disimiles que estas fueran - bajo la misma categoría identificatoria, a pesar del hecho de que los militares conocían bien las diferencias en el pensamiento de las distintas agrupaciones, partidos y grupos políticos que intentaban transformar la realidad social ${ }^{8}$. Es justamente la categoría identificatoria de "subversivo" la que funcionó como una marca indeleble que permitió al PRN unificar e identificar a su “enemigo" y aplicar sobre él todo el peso del Estado terrorista.

En este sentido la categoría de subversivo le permitió al Estado Terrorista identificar a una gran variedad de prácticas bajo una misma lógica. Esta operación discursiva y práctica invisibilizó las características específicas de cada uno de los movimientos políticos, así fue posible dar el mismo trato a una comunidad India luchando por su derecho a la tierra que a un combatiente del Partido Revolucionario de los Trabajadores y su brazo armado el Ejército Revolucionario del Pueblo (PRT-ERP), bajo la lupa genocida todos son el enemigo, todos son "subversivos".

La subversión es toda acción clandestina o abierta, insidiosa o violenta que busca la alteración o la destrucción de los criterios morales y la forma de vida de un pueblo,

7 CALVEIRO, Pilar, Poder y desaparición. Los campos de concentración en Argentina, Buenos Aires, Colihue, 2008.

8 El conocimiento militar de las distintas posiciones políticas queda de manifiesto en los documentos elaborados por la última dictadura militar, particularmente en el titulado ANÓNIMO, La Subversión en el ámbito educativo (Conozcamos a nuestro enemigo), Buenos Aires, Ministerio de Cultura y Educación, 1977, disponible en URL: < http://www.bnm.me.gov.ar/giga1/documentos/ELo03637.pdf $>$ [consultado el 15 de septiembre de 2015]. 
con la finalidad de tomar el poder o imponer desde él una nueva forma basada en una escala de valores diferentes ${ }^{9}$.

Una segunda operación discursiva, consistió en considerar las acciones "subversivas" como extranjeras, es decir como elementos importados y sin carta de ciudadanía. Una interpretación que supone que son estos “otros" influenciados por lógicas extranjeras del «marxismo internacional»10 los que invaden el territorio y la cultura nacional. Esto podría ser definido como un proceso de extranjerización de ciudadanos argentinos. En efecto la dictadura sabe que las personas que categorizan de subversivos son argentinos, pero los extranjeriza, los pone afuera, de alguna manera los sitúa en lo que Agamben ${ }^{11}$ denomina el umbral. Este proceso de extranjerización puede ser rastreado en el período 73-76 muy bien estudiado por Marina Franco ${ }^{12}$.

Al mismo tiempo que se desarrollo este proceso de negación física y simbólica, también se intentó llevar a cabo un proceso de afirmación de lo que se consideraba "el amigo", sintetizado en la categoría del "ser nacional". Estos procesos se encuentran conectados a través de líneas de comunicación, se infieren el uno en el otro, en otras palabras, esta lógica que se propone como binaria obliga a tener en cuenta que ambos procesos se desarrollan al unísono conectados a través de ese "entre sí" al que venimos haciendo referencia. Así amigo/enemigo, mismidad/otredad, afirmación/negación son procesos que se deben analizar simultáneamente. Esto es así no solo porque lo exige el discurso sino también porque en la práctica se llevó a cabo de la misma manera. Para decirlo de forma más directa, al mismo tiempo que desaparecían personas sus prácticas y discursos también se llevaba a cabo el ascenso de otras que ocupaban los espacios vaciados por la represión ilegal.

Ahora bien, los procesos de afirmación/negación se relacionan con la capacidad para imponer un discurso e instigar a la realización de prácticas. En efecto como nos recuerda Nelly Richard ${ }^{13}$ para el caso chileno las identidades previas al golpe no desaparecieron por la intervención militar y la imposición de nuevas categorías identificatorias, sino que se sumaron. Así los agentes no hicieron tabula raza con la

9 Ibídem, p. 16. [consultado el 17 de octubre de 2015].

${ }^{10}$ Los documentos militares insisten en considerar al pensamiento "subversivo" como parte de un plan de intervención gestado por lo que denominan "marxismo internacional" dando lugar a una interpretación polarizada típica de la guerra fría detrás de la cual se encuentran especulaciones económicas.

${ }^{11}$ AGAMBEN, Giorgio, Estado de excepción. Homo sacer II, Buenos Aires, Adriana Hidalgo, 2007.

${ }_{12}$ MARINA, Franco, Un enemigo para la nación. Orden interno, violencia y "subversión", 19731976, Buenos Aires, Fondo de Cultura Económica, 2012.

${ }_{13}$ NELLY, Richard, Fracturas de la memoria. Arte y pensamiento crítico, Buenos Aires, Siglo XXI Ed., 2007. 
llegada del golpe de facto sino por el contrario algunos se aprovecharon de su identificación previa para ocupar espacios de poder mientras otros se encontraron en el ojo de la tormenta.

Así, las identificaciones que no coincidieron con la ideología del PRN se vieron invisibilizadas por la capacidad del Estado Terrorista de ejercer la represión ilegal y cooptar los discursos legitimados. Aunque las personas se siguieran identificando de distintas formas: como Montoneros, PRT-ERP, Pueblos Originarios, en la práctica estos discursos solo pudieron circular por espacios muy reducidos. Mientras, la fuerza con que la dictadura puso en práctica sus estrategias, logro cooptar los discursos legitimados e imponerse a una importante porción de la sociedad.

Lo que hemos intentado mostrar es que la lógica aparentemente sencilla de amigo/enemigo oculta detrás de sí una gran complejidad en la que confluyen una gran serie de procesos sociales constitutivos de la mismidad y simultáneamente de la otredad. Sin embargo la perspectiva gráfica con la que se presenta ésta lógica binaria hace difícil observar las fracturas en el interior de sus discurso y prácticas, es esa barrera (/) que divide y une ambas categorías la que nos permitirá debelar las grietas.

\section{El funcionamiento del DGI en Tafí del Valle (Tucumán)}

Es importante aclarar que el funcionamiento del DGI se encuentra espacializado, es decir se reacomoda de acuerdo a las características específicas de las relaciones de poder. En este sentido el mayor desarrollo de un discurso identitario estatal nos estaría señalando la necesidad del Estado Nación de ampliar el rango de acción del DGI. Por esta razón consideramos de particular importancia observar cómo se despliega el dispositivo en un espacio específico, en otras palabras proponemos observar el poder allí donde este se aplica.

Como vemos el DGI incluye una gran variedad de discursos y prácticas que conforman una red que funciona coordinadamente sin ser coordinada. De esta forma, al analizar uno de los puntos del dispositivo es posible reconstruir al menos una porción de la red. La reformulación del DGI realizada por la dictadura reformuló el binomio ciudadano/extranjero por el de delincuente-subersivo/ser nacional-argentino. Como vimos esta traducción implicó considerar a todos aquellos que hicieran uso de su libertad política ${ }^{14}$ como subversivos y por ende extranjeros y marxistas. Pero también intentó crear una identidad esencialista que recobrase elementos simbólicamente

14 FEIERSTEIN, Daniel, op. cit., p. 340. 
efectivos con el fin de fortalecer la idea de que los argentinos somos todos occidentales y cristianos.

Al referirnos al Departamento de Tafí del Valle ${ }^{15}$, esta idea entra en colisión directa con los procesos de resistencia que los Pueblos Originarios venían desarrollando. Veamos brevemente como se llevaba a cabo la vida en este lugar. El departamento de Tafí del Valle se caracterizó desde el período colonial por la existencia de propietarios latifundistas que propiciaron una explotación extensiva con campesinos arrendatarios. El desarrollo de la industria azucarera agrego otro elemento a la relación de utilidad y dependencia en la relación patrón/campesino, el ya mencionado arriendo y la obligación de trabajar en la zafra azucarera ${ }^{16}$.

El “Operativo Tucumán” generó un shock en esta relación, el proceso de "racionalización" de la industria azucarera conocido como "cerrojazo" tuvo como resultado el cierre de 11 de los 27 ingenios tucumanos afectando a 25.000 personas ${ }^{17}$. La transformación de la lógica de ocupación de los terratenientes, quienes pasan de una lógica campesina a una empresarial. Esta última suponía un mayor control del espacio que resultó en la aparición de nuevos alambrados que privaron de la libre circulación a las personas. Lo que daría un golpe definitivo a la relación patrón/campesino. En este ambiente comenzó a desarrollarse un proceso de activación política que tuvo como eje la identificación con un pasado en común. Este proceso ancló en el reconocimiento de su pertenencia a los "Pueblos Originarios", en las vejaciones sufridas bajo el régimen terrateniente y en el trabajo de la tierra.

Este proceso llevó a la conformación de acciones que los entrevistados denominan "la lucha" donde lo que se peticionaba era el derecho a la tenencia de la tierra. Fue esta reacción la que impulsó la creación de una Federación India y la puesta en práctica de acciones públicas de confrontación al orden instituido por los terratenientes. La respuesta no se hizo esperar, la intervención de las fuerzas represivas en Tucumán comienza muy tempranamente con la llegada de la gendarmería nacional en el año '74

15La provincia de Tucumán se ubica al noroeste de la República Argentina, tiene 1.338.523 habitantes (INDEC 2001). El territorio está dividido en 17 departamentos, cada uno de los cuales tiene municipalidades o comunas rurales, en el caso de pequeñas poblaciones. El Departamento de Tafí del Valle posee una superficie de $2.741 \mathrm{~km}^{2}$ e incluye el Municipio de Tafí del Valle y las comunas de El Mollar, Amaicha del Valle, Ampimpa, El Tío, Colalao del Valle y El Pichao. El Municipio cabecera es Tafí del Valle, el cual se encuentra ubicado sobre la Ruta Provincial No 307 (pavimentada), a $120 \mathrm{Km}$. al oeste de la ciudad de San Miguel de Tucumán. La misma ruta comunica hacia el NO la localidad de Tafí con el Valle de Amaicha, y a través de la Ruta $\mathrm{N}^{\circ} 40$ (pavimentada), hacia el Sur con la ciudad de Santa María (Provincia de Catamarca) y hacia el Norte con Cafayate (Provincia de Salta).

${ }_{16}$ BOLSÍ, Alfredo, El hombre y el medio en el Valle de Tafi: informes y avances, Tucumán. Universidad Nacional de Tucumán, 1991, p. 15.

${ }_{17}$ PUCCI, Roberto, Historia de la destrucción de una provincia. Tucumán 1966, Buenos Aires, Ediciones del Pago Chico, 2007, p. 19. 
poco tiempo después la presidenta Isabel Martinez de Perón firmaría el decreto 225 el cual autorizaría al uso de la fuerza para eliminar la subversión en Tucumán así comenzó el denominado "Operativo Independencia”, el cual sirvió como experimento de prácticas genocidas, posteriormente la dictadura se encargaría de llevarlo a nivel nacional. En el Departamento de Tafí del Valle la puesta en práctica de la represión ilegal se encargó puntualmente de cercenar el movimiento mediante la captura de sus líderes y acciones públicas de amedrentamiento. Al mismo tiempo se llevo a cabo un proceso de negación/afirmación que utilizó todos los discursos legitimados a su mano. Tomemos de ejemplo la reconstrucción de la "Ruinas de Quilmes"18 actualmente denominada por los Pueblos Originarios como "Ciudad Sagrada”.

Un primer acto de índole política es la nominación patrimonial realizada por la ley 4398/75 que lo establecía como monumento histórico. Bien entrada la última dictadura militar en el año '77 se firma un convenio con el Instituto Interdisciplinario Tilcara ${ }^{19}$ (IIT) de la Universidad de Buenos Aires (UBA) para llevar a cabo un proceso de reconstrucción arqueológica, la elección de ésta institución tiene relación con una postura política sostenida por los directivos del IIT desde su fundación con el Dr. Casanova y su continuación con el Lic. Pelissero ${ }^{20}$. Es esta identificación la que incentivó la elección del IIT como productor de un discurso valido y necesario para realizar los trabajos. A este requisito se le sumó la experiencia previa del Pucara de Tilcara. Esta forma de actuar, en la que se combina el reconocimiento académico y la identificación política fue moneda corriente en la gestión cultural y universitaria realizada por el PRN.

A continuación quisiera realizar una pequeña digresión que confío ilustrará este punto. En la Facultad de Filosofía y Letras (FFyL) de la Universidad Nacional de Tucumán (UNT), se llevó a cabo un proceso de expulsión de todos aquellos docentes considerados como subversivos. Como es bien sabido los procesos de expulsión fueron

\footnotetext{
${ }^{18}$ El yacimiento de las "Ruinas de Quilmes" es una ciudad precolombina que resistió los embates españoles hasta el fin del segundo levantamiento calchaquí.

19 El Museo e Instituto Interdisciplinario Tilcara es una institución creada por la facultad de Filosofía y Letras de la Universidad de Buenos Aires (UBA) en el año 1966 con la venia del por entonces Decano Interventor Horacio Difrieri quién impulsa el desarrollo del museo largamente postergado desde 1908 cuando el Dr. Ambrossetti estudiara las ruinas de un Pucara en la comuna del Pueblo de Tilcara ubicado en la Quebrada de Humahuaca (provincia de Jujuy). Este espacio se configuró como un lugar de conocimiento legítimo y claramente identificado como anti-peronistas.

${ }^{20}$ SLAVUTSKY, Ariel Ignacio, Patrimonio y Dictadura. Los procesos de patrimonialización en el Departamento de Tafi del Valle durante la última dictadura militar Argentina (1976-1983). Los procesos identitarios en contextos represivos, Tesis Doctoral en Ciencias Sociales, Universidad Nacional de Tucumán, 2014.
} 
desde las cesantías hasta la desaparición ${ }^{21}$, pero alguien debía ocupar ese espacio de poder y la selección no tuvo que ver sólo con las manifestaciones realizadas al calor del golpe sino que los militares conocían bien las posiciones políticas previas y realizaron una selección de aquellos que consideraban afín a su proyecto político e identitario. Así el gobierno de la FFyL de la UNT no fue confiado a un delegado militar ni a una persona recién llegada, le fue legado al Profesor Orlando Lázaro quien ya tenía un largo historial de apoyo a los golpes militares, de hecho el 24 de marzo de 1976 lo encuentra ocupando el decanato que seguirá ocupando hasta el año siguiente, será durante este primer año cuando se produjo la mayor cantidad de expulsiones y de nombramientos.

Regresando a la gestión de la Ciudad Sagrada, la reconstrucción se realizó teniendo en cuenta el modelo tilcareño, mano de obra local controlada por un grupo de Arqueólogos. A cargo de la selección de los obreros estuvo el intendente Gonzalo Paz quién además era terrateniente de la zona, Becerra y otros ${ }^{22}$, muestran en su trabajo que la selección fue de la mano con el sistema de obligaciones por arriendo, al mismo tiempo los lugareños fueron elegidos por su reconocida experticia en el uso de las técnicas tradicionales de construcción.

Otro elemento no menor fue la privatización del yacimiento arqueológico siguiendo las lógicas patrimonialistas. A partir de la intervención del Estado se produce un proceso de alienación del bien cultural activado separándolo de la vida cotidiana de los habitantes, la aparición de la fuerza policial en la zona y la construcción de muros alrededor de un lugar antes abierto a las prácticas cotidianas intentó cercenar simbólicamente a los "Pueblos Originarios" de su Historia, años después la Comunidad India de Quilmes recuperaría ese espació como un símbolo de empoderamiento.

Ahora bien, el campo académico produce también un discurso legitimado y reconocido que se replica en los distintos ámbitos del DGI, así algo dicho por los arqueólogos se repitió en los discursos de la prensa, de los políticos y de los maestros, entre otros, llegando a constituirse en una suerte de discurso oficial. Veamos algunas operaciones discursivas:

${ }^{21}$ Véase: SLAVUTSKY, Ariel Ignacio, «The Professors and Student Identification in Tucumán National University during the Last Argentinean Dictatorship», in International Journal for Humanities and Social Sciences, 5, 2/2015, URL: < http://www.ijhssnet.com/journal/index/2951 > [consultado el 9 de mayo de 2015]. ${ }_{22}$ BECERRA, María Florencia (et. al.), «Dinámicas de poder y saber en la reconstrucción de la Ciudad Sagrada de Quilmes (Tucumán 1977-1981)», in Revista Alteridades, XXIII, 46, 2013, pp. 67-77. 


\subsection{Pueblos desaparecidos. La total desaparición de los indios Quilmes}

Estas operaciones particulares del discurso tienen una misión pedagógica que es retomada en los discursos periodísticos, donde se dejan en claro dos situaciones: la total desaparición de los indios Quilmes y la importancia turística del lugar.

Los conquistadores españoles, vencieron por sitio. Fue una resistencia dramática allá por 1667. Muchos murieron de hambre. Y hasta optaron por matar a sus hijos para no rendirlos. Los españoles llevaron a los sobrevivientes, unos 2000, a Buenos Aires. Todos eran personas muy mayores por lo que la descendencia fue muy escasa. Lo único que pidieron fue, en su derrota, que el lugar donde se ubicara se llamara Quilmes. Así nació esa ciudad bonaerense. Y allí murió el último de los indígenas auténticos a fines del siglo pasado. Pero las huellas que dejaron aquí en el Norte fueron rotundas. Y ahora queremos redimirlas. Este trabajo, pues, tiene una significación muy honda para Tucumán y la Argentina²3.

En cuanto a la segunda, se comienza a avizorar los primeros pasos de un plan turístico para el NOA argentino, que se uniría con los de otros países que conformarán luego lo que actualmente denominamos el camino del Inca; el discurso que sostiene la total desaparición de los pueblos Quilmes lleva a cabo un proceso de invisibilización y no reconocimiento de las comunidades indígenas descendientes (entre ellas la Comunidad Indigena de Amaicha del Valle que aún sigue existiendo), al mismo tiempo, se reconoce su participación en la Historia Argentina. De esta forma, las culturas originarias desaparecen como sustento físico (los Quilmes) y reaparece de forma fantasmática en elementos simbólicos que en las fuentes dan contenido al término tradición.

Este tipo discurso puede encontrarse en una carta enviada por el Dr. Casanova a Marvin Bertini el 6 de enero de 1968 en ocasión de la creación de la estatua de un indio en la cima del pucará donde afirma:

Lo correspondiente a características raciales, especialmente de las fracciones debe ser consultado con el Dr. Bórmida, Director del Instituto de Antropología de la Facultad. En la zona ya no existen indígenas racialmente puros o siquiera poco mestizados, por lo tanto la reconstrucción física tiene que hacerse según los datos

23 PELISSERO, Norberto, «La historia de los Quilmes», in La Gaceta, 26 de enero de 1978, p. 6. 
que proporcionen los especialistas. Dada la similitud con los pobladores indígenas actuales del altiplano boliviano creo que sus rasgos podrían servir de guía ${ }^{24}$.

La búsqueda de una caricatura estereotipada con una supuesta pureza racial y cultural, que al estar influida por las culturas occidentales blancas dejan de existir y se transforman en otra figura. Esto permite desconocer los derechos de los pueblos originarios actuales.

En la siguiente cita el Lic. Norberto Pelissero en su carácter de director de Instituto Tilcara responde a un pedido del director general de Desarrollo Social, Horacio Gómez el que pregunta sobre la existencia de pueblos originarios en la zona sur de la provincia de Jujuy y concluye que:

La pérdida de la lengua y el avanzado y continuo proceso de aculturación de los grupos aborígenes de la provincia de Jujuy nos lleva a afirmar que no es correcto, por lo menos en este caso, de hablar de población o grupos aborígenes, sino que es más exacto definir a los distintos grupos humanos como criollos o campesinos y a partir de esta estructura plantear el marco referencial que sirva de punto de partida para implementar las políticas de desarrollo que usted desee ${ }^{25}$.

Para la corriente de pensamiento asumida por una gran parte de los arqueólogos argentinos del momento, la presencia de una lengua activa contribuía a definir la presencia indígena en tiempo presente, a punto tal que su ausencia es el recurso que autoriza a una clasificación de las personas por afuera de su condición étnica. Es con esta impronta que la afirmación del director del IIT reubica la presencia de prácticas indígenas como supervivencias, pero niega la existencia de una cultura viva; con su accionar legitima y habilita cualquier intervención. Su postura académica congruente con su posición política hizo posible su actuación en puestos destacados.

\section{2. "Pueblo Primitivo"}

Otra de las consecuencias de la invisibilización discursiva de los pueblos originarios es la generalización de los mismos como pueblos primitivos vinculados a la naturaleza. Esto se puede observar en este párrafo escrito por Pelissero:

24 Véase: Carta (inédita) de Eduardo Casanova a Mario Marvin Bertini (6 de enero de 1968), Archivo del Instituto Interdisciplinario Tilcara (ITT), Caja 4, Doc. 15.

${ }^{25}$ Carta (inédita) de Lic. Pelissero a N. Gómez (9 de mayo de 1981), Archivo del ITT, Caja 5, Doc. 16. 
Creemos que el hombre primitivo, en su íntima relación con el medio, realzaba su expresión gráfica como un modo de comunicación con la Naturaleza, con esa "otra" potencia con la cual estaba en situación de continuo intercambio. Es así como la obra de arte puede adquirir, ante los herederos generacionales de sus autores, una potencialidad distinta, además de un destinatario potente diverso. Es aquí donde reside principalmente la dificultad de asignar un valor o una significación a las manifestaciones gráficas del mundo primitivo. De lo que sí estamos convencidos es de que nada ha sido hecho por los grupos aborígenes que no sea referido a lo concreto relacionado con ese diálogo constante sostenido por aquellos y el mundo circundante ${ }^{26}$.

La clasificación de "primitivo" da lugar a un juicio de valor en el que los pueblos originarios están inmersos en el mundo natural y lejos de apuntar al control de la naturaleza son parte de ella, su cosmovisión expresa una relación dialógica con el mundo circundante, lo que no implica que no contaran con los recursos reflexivos para atender lo inefable o imprevisto, tal vez el arte pueda ser un vehículo tanto emocional como reflexivo, y no meramente una expresión que deba ser interpretada a luz del presente. Quienes interpretan en tiempo presente, los pueblos originarios cuentan con la memoria, expresada en cuentos, chistes, anécdotas, narraciones que atraviesan generaciones, y habilitan la idea de culturas originarias transformadas dialécticamente, pero presentes.

En otro lugar de enunciación en el que podemos encontrar una visión similar es en el terreno de la educación primaria y secundaria. Este sector fue uno de los más controlados por la administración del gobierno militar: en el ámbito docente, con el despido, desaparición o traslado de una gran parte de los docentes y directores del nivel; en el sindical con la suspensión del estatuto docente así como de las juntas de clasificación; en el curricular, con el cambio en las currículas de todas las materias del nivel inicial y secundario. En la materia Historia el período que abarca desde la invasión Europea a América hasta la década de 1880 se establecen como contenidos mínimos:

Las civilizaciones prehispánicas con inclusión del territorio argentino.

Conquista con especial referencia al territorio argentino.

${ }^{26}$ PELISSERO, Norberto, Los petroglifos del Angosto de Ucumazo de Humahuaca, Tomo XXX, Barcelona, Ampurías, 1968, p. 272. 
Los problemas territoriales. Patagonia, Chaco. Misiones. Integración efectiva del territorio nacional ${ }^{27}$.

En esta cita queda claro que los indios son concebidos como un estorbo en el progreso del modelo civilizatorio. La denominación de «problemas territoriales e integración efectiva» connota que las campañas de dominación llevadas a cabo desde principios de la década de 1880, permitieron eliminar un elemento de primitivismo que impedía el desarrollo.

En las Actas del Consejo Federal de Cultura y Educación de agosto de 1981, en la Recomendación 5/81 sobre la protección de las artesanías tradicionales no se hace referencia en ningún momento a la población originaria, incluso cuando se realiza una encuesta para recabar los datos de los artesanos, se pregunta el domicilio actual, domicilios anteriores, fecha y lugar de nacimiento pero en ningún momento se hace referencia a la etnia o cultura a la que pertenece el sujeto encuestado. Lo que está relacionado con la invisibilización de los sujetos reales, al mismo tiempo que se reconoce su participación en la elaboración de artesanía y el patrimonio nacional.

Lo que oculta esta visión de los pueblos originarios considerados "primitivos" es una visión lineal de la historia en la cual se encuentran incluidas las fases prehistóricas, la conquista y evangelización europea, la integración nacional definitiva, la argentina del modelo agroexportador, el peronismo, la "restauración libertadora" y finalmente el proceso de reorganización nacional que en un acto de salvación evita la desaparición de la nación.

Estas operaciones discursivas y prácticas funcionan como una herramienta para la dominación cultural, permitiendo al PRN, al gobierno provincial y municipal no solo reorganizar las relaciones de poder sino también construir una narrativa para fortalecer una identidad "occidental y cristiana”.

\section{Reflexiones finales}

¿Cómo se comportan las personas en las grietas? El "entre sí" funciona como un espacio donde la reflexividad de los agentes y su capacidad para desarrollar estrategias que hagan jugar los habitus propios de un campo específico pero también de otros ajenos, así discursos y prácticas de distintos campos se interceptan, vulnerando las

27 Consejo Federal de Educación - VII Asamblea extraordinaria (Informe final, recomendación $n^{\circ} 7$ ). Actas del Consejo Federal de Cultura y Educación (18-19 de diciembre de 1978), Buenos Aires, Centro Nacional de Documentación e Información Educativa, 1978, pp. 154-158. 
autonomías relativas. Sin embargo, esto no quiere decir que el habitus de un campo específico se acomode rápidamente a la coyuntura de las relaciones de poder sino que en muchas ocasiones se llevan a cabo acciones vedadas y se actúa como si el entrecruzamiento de influencias y disposiciones no hubiera ocurrido. En el caso tanto de IIT como del Decano Interventor Orlando Lazaro se observa como en la práctica los distintos elementos y espacios constitutivos de la subjetividad de una persona funcionan coordinadamente y es ésta capacidad la que hace funcionar estos distintos espacios y discursos a favor suyo.

Los elementos del DGI entonces funcionan coordinadamente sin estar del todo coordinados, esto es así porque son las voluntades de los agentes los que continuamente están haciendo jugar las distintas posiciones. En el caso estudiado de la gestión del patrimonio cultural y particularmente de la "Ciudad Sagrada de Quilmes", los discursos y las prácticas investigativas, la política y el periodismo parecen actuar con lógicas prácticas propias sin embargo cuando se observa el juego de las interrelaciones en un contexto específico, las prácticas parecen estar coordinadas, esto no es porque los agentes lo hayan planeado de esa forma sino porque interpretaron la coyuntura de la misma manera e intentaron sacar rédito de su posición. Así, la vida se proyecta como un sin número de acuerdos sin acuerdos de casualidades no tan casuales y de causalidades no tan causales. 


\section{* El autor}

Ariel Ignacio Slavutsky es Doctor en Ciencias Sociales por la Universidad Nacional de Jujuy y desarrolla investigaciones (es Becario posdoctoral del CONICET) en torno a la relación entre cultura y dictadura militar. Ha publicado en las revistas «International Journal for Humanities and Social Sciences», «Cuadernos FHyCS-UNJU» y «Revista de la Escuela de Antropologia de la UNR».

URL: < http://www.studistorici.com/progett/autori/\#Slavutsky >

\section{Per citare questo articolo:}

SLAVUTSKY, Ariel Ignacio, «El funcionamiento del Dispositivo Generador de Identidades durante la última dictadura militar argentina (1975-1983)», Diacronie. Studi di Storia Contemporanea : Le dittature militari: fisionomia ed eredità politica, 29/12/2015,

URL:< http://www.studistorici.com/2015/12/29/slavutsky_numero_24/ >

\section{Diacronie Studi di Storia Contemporanea $\beta$ www.diacronie.it}

Risorsa digitale indipendente a carattere storiografico. Uscita trimestrale. redazione.diacronie@hotmail.it

Comitato di redazione: Jacopo Bassi - Luca Bufarale - Elisa Grandi - Antonio César Moreno Cantano - Deborah Paci - Fausto Pietrancosta - Alessandro Salvador - Matteo Tomasoni - Luca Zuccolo

Diritti: gli articoli di Diacronie. Studi di Storia Contemporanea sono pubblicati sotto licenza Creative Commons 3.0. Possono essere riprodotti e modificati a patto di indicare eventuali modifiche dei contenuti, di riconoscere la paternità dell'opera e di condividerla allo stesso modo. La citazione di estratti è comunque sempre autorizzata, nei limiti previsti dalla legge. 